\title{
Comportamento de concretos com fibras de poliolefina sob elevadas temperaturas
}

Este trabalho tem por objetivo apresentar resultados do sobre o comportamento do concreto com fibra de poliolefina submetido a elevadas temperaturas. A partir dos resultados de ensaios de aquecimento até de $900^{\circ} \mathrm{C}$ em corpos de prova de concreto cilíndricos (fc de $35 \mathrm{MPa}$ sob temperatura ambiente), apresentam-se os

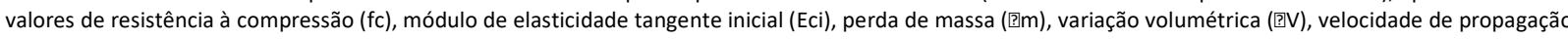
de onda ultrassônica $(V)$, resistência à tração (fct, sp) e porosidade (n), além da verificação da ocorrência de spalling. Verificou-se que o uso da fibra melhorou as características mecânicas residuais do concreto submetido a elevadas temperaturas.

Palavras-chave: Propriedades Mecânicas; Concreto com Fibras; Elevada Temperatura; Poliolefina.

\section{Studies on the behavior of polyolefin fiber reinforced concrete at high temperatures}

This work aims to present results of studies on the behavior of polyolefin reinforced concrete at high temperatures. From the heating test results up to about 900 ${ }^{\circ} \mathrm{C}$ in cylindrical concrete specimens (fc $35 \mathrm{MPa}$ at ambient temperature), the values of compressive strength (fc), modulus of elasticity (Eci), mass loss (?m),

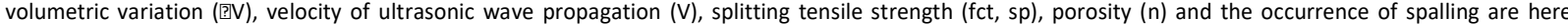
presented. It was found that the residual mechanical characteristics were improved with the use of fiber at elevated temperatures.

Keywords: Mechanical Properties; Fiber Reinforced Concrete; High Temperature; Polyolefin.

Topic: Sustentabilidade nos Transportes

Reviewed anonymously in the process of blind peer.
Received: 10/02/2018

Approved: 24/03/2018
Celso Andre Moreira da Rocha

Instituto Militar de Engenharia, Brasil

http://lattes.cnpq.br/3605318737324130

celsorocha@outlook.com

Luiz Antonio Vieira Carneiro

Instituto Militar de Engenharia, Brasil

http://lattes.cnpq.br/2431901858566512

carneiro@ime.eb.br

Ana Maria Abreu Jorge Teixeira

Instituto Militar de Engenharia, Brasil

http://lattes.cnpq.br/1454254574734029

anam@ime.eb.br
Referencing this:

ROCHA, C. A. M.; CARNEIRO, L. A. V.; TEIXEIRA, A. M. A. J..

Comportamento de concretos com fibras de poliolefina sob elevadas temperaturas. Revista Ibero Americana de Ciências Ambientais, v.9, n.3, p.219-233, 2018. DOI: http://doi.org/10.6008/CBPC2179$\underline{6858.2018 .003 .0018}$ 


\section{INTRODUÇÃO}

O efeito de elevadas temperaturas no concreto é um assunto que deve ser levado em consideração na análise da segurança das estruturas, pois a exposição contínua a elevadas temperaturas causa diversos efeitos deletérios no concreto, os quais contribuem para a diminuição da capacidade portante das estruturas. O concreto é incombustível e não produz emissões tóxicas quando exposto ao fogo (MEHTA et al., 2014).

Para minimizar os efeitos das elevadas temperaturas sobre o concreto, o uso de fibras tem sido estudado. De fato, na construção civil, a crescente utilização de fibras como compósito do concreto pode ser vislumbrada em vários tipos de aplicações, destacando-se em concretos para pavimentos e para revestimentos de túneis (FIGUEIREDO, 2005).

O desenvolvimento de novas fibras sintéticas tem proporcionado ganhos nas propriedades mecânicas do concreto. Dentre estas fibras, as fibras de poliolefina podem levar a um comportamento pósruptura próximo ao de um concreto com fibras de aço, para um baixo teor volumétrico de fibras. Estas novas fibras sintéticas proporcionam uma alternativa quando a adição de fibras é necessária e o uso de fibras de aço não é recomendável (ALBERTI et al., 2015), como em ambientes agressivos onde a corrosão das fibras pode ser uma preocupação.

Apesar de tais características, há poucos estudos na literatura sobre o uso das fibras de poliolefina em concretos submetidos a elevadas temperaturas. Com um baixo ponto de fusão (em torno de $150{ }^{\circ} \mathrm{C}$ ), semelhante ao das fibras de polipropileno, torna-se interessante tal estudo, tendo em vista que as fibras de polipropileno podem evitar o lascamento explosivo (spalling, no seu termo em inglês) nas estruturas em situação de incêndio (de fato, Eurocode 2 indica seu uso para este fim), e caso as fibras de poliolefina possam replicar tal característica, podem ser também um substituto às fibras de polipropileno, com as vantagens já citadas de levarem a um comportamento próximo ao das fibras de aço. A presente pesquisa visa estudar o comportamento do concreto com fibras de poliolefina, quando aquecido a temperaturas de até $900{ }^{\circ} \mathrm{C}$, em termos das suas as propriedades físicas e mecânicas.

\section{REVISÃO TEÓRICA}

\section{Concreto com fibras}

Concretos contendo um cimento hidráulico, água, agregados e fibras discretas descontínuas aleatoriamente dispersas no seu interior é chamado de fiber reinforced concrete, aqui chamado de concreto com fibras. As fibras alteram as características mecânicas do concreto, que dependem do seu tipo, geometria e teor volumétrico $(\mathrm{Vf})$.

De acordo com Bentur et al. (2007), materiais cimentícios sem fibras são caracterizados por baixa resistência à tração e baixa capacidade de deformação à tração, tornando-os frágeis. Estes requerem reforço para o uso extensivo como materiais de construção. Historicamente, este reforço tem sido executado na forma de barras de aço contínuas, as quais devem ser colocadas na estrutura em locais apropriados, para resistir à tração. Fibras, por outro lado, são descontínuas, e dispersas de maneira aleatória na matriz 
cimentícia, não sendo tão eficientes em resistir à tração. Contudo, devido ao fato de que elas tendem a possuir um espaçamento menor do que as barras de aço, elas são melhores no controle de formação e abertura de fissuras. Assim, as barras de aço convencionais são utilizadas para amentar a capacidade de carga do concreto, enquanto as fibras são melhores no controle de fissuras.

O principal mecanismo de atuação das fibras no concreto trata de prevenir ou controlar a abertura de fissuras. Dependendo de suas características, as fibras podem atuar tanto nas microfissuras quanto nas macrofissuras, no trecho pós-pico de resistência, conferindo um aumento significativo da energia associada à ruptura do material. No primeiro caso, pode-se ter aumento da resistência, enquanto no segundo, incremento de ductilidade e tenacidade (MILLER, 2008).

Especificamente com relação ao presente estudo, sob temperatura ambiente, o concreto com fibras de poliolefina apresenta características similares às do concreto com fibras de aço. A adição de fibras de poliolefina no concreto pode aumentar sua resistência à flexão em até $13 \%$ e reduzir sua fissuração em até $70 \%$, em comparação com corpos de prova de concreto sem fibras. Ainda, a resistência ao impacto de concretos com fibras de poliolefina é duas vezes maior do que a de concretos com fibras de aço e quatorze vezes maior do que a de concretos sem fibras (LIN et al., 2011).

As fibras de poliolefina apresentam uma boa aderência à matriz de concreto, devido à sua rugosidade superficial, tendo muitos dos mesmos efeitos das fibras de polipropileno na resistência do concreto com fibras, sendo particularmente efetivas contra o impacto. Elas também aumentam consideravelmente a resistência à fadiga (BENTUR et al., 2007).

\section{Efeitos das elevadas temperaturas no concreto}

O comportamento do concreto exposto a altas temperaturas é o resultado de diversos fatores cujas interações simultâneas são muito complexas para uma análise precisa (METHA et al., 2014). Em geral, o concreto apresenta boa resistência ao calor devido a sua baixa condutividade térmica. Sob altas temperaturas, o concreto é incombustível e não emite gases tóxicos, além de conservar resistência suficiente em período razoavelmente longo para temperaturas na ordem de $700^{\circ} \mathrm{C}$ a $800^{\circ} \mathrm{C}$ (METHA et al., 2014).

Ainda de acordo com Metha et al. (2014), o efeito do aumento de temperatura na pasta hidratada de cimento depende do grau de hidratação e da umidade. Uma pasta de cimento bem hidratada consiste principalmente de silicato de cálcio hidratado (C-S-H), hidróxido de cálcio e sulfoaluminato de cálcio hidratado. Quando a temperatura atinge $300{ }^{\circ} \mathrm{C}$, a água entre as camadas de $\mathrm{C}-\mathrm{S}-\mathrm{H}$, e parte da água quimicamente combinada do C-S-H e sulfoaluminato hidratado, são evaporadas. A cerca de $500{ }^{\circ} \mathrm{C}$, há desidratação adicional da pasta de cimento devida à decomposição do hidróxido de cálcio, mas temperaturas da ordem de $900^{\circ} \mathrm{C}$ são necessárias para a decomposição completa do C-S-H. O tipo do agregado possui uma grande influência na resposta do concreto ao fogo. Parte da fissuração que ocorre no concreto é devido à diferença de expansão entre o agregado graúdo e a argamassa.

Os agregados silicosos, que contêm quartzo (granito ou arenito), podem danificar o concreto a uma temperatura de $573^{\circ} \mathrm{C}$, pois, nesta temperatura, a transformação do quartzo de $\alpha$ para $\beta$ resulta em uma 
expansão da ordem de $0,85 \%$, o que favorece a microfissuração do concreto. No caso de rochas carbonáticas, um dano similar pode começar acima de $700{ }^{\circ} \mathrm{C}$ como resultado da reação de descarbonização (MEHTA et al., 2014). Esta característica torna a resposta à exposição a elevadas temperaturas dos concretos feitos com agregados silicosos, diferente dos concretos feitos com agregados calcários.

Outro efeito das elevadas temperaturas sobre o concreto é o spalling (lascamento explosivo) do concreto. É de conhecimento geral que a água pode estar presente em diversas formas na pasta de cimento. Os vários tipos de água são evaporados ao elevar-se a temperatura e a temperatura no interior do concreto não se eleva até que toda a água evaporável seja removida.

O spalling resulta de dois processos concomitantes, um processo termomecânico, associado a gradientes térmicos de dilatação/retração que ocorrem dentro do elemento sendo aquecido e um processo termohidráulico, que gera campos de gás de alta pressão (água evaporada e ar) na rede de poros (KALIFA et al., 2001). De fato, a elevação da pressão interna decorrente da evaporação da água tem uma influência muito grande na ocorrência do spalling (KALIFA et al., 2001; BEHNOOD et al., 2009; AKCA et al., 2013).

Entre os métodos utilizados para controlar o spalling, a adição de fibras de polipropileno (PP) ao concreto parece ser bastante eficiente. As fibras de PP fundem-se a $170^{\circ} \mathrm{C}$. Quando fundidas e parcialmente absorvidas pela matriz de cimento, as fibras abrem um caminho para escape do o gás no interior do concreto. Desta forma, elas contribuem para formar uma rede de poros mais permeável, que facilita a saída do gás e resulta na redução da poro pressão (KALIFA et al., 2001).

As alterações sofridas pelo concreto influenciam na redução dos valores de suas propriedades mecânicas, o que tem levado a diversos pesquisadores estudarem tais efeitos. Abrams (1971) conduziu um estudo de quatro variáveis, incluindo tipos de agregado (silicoso, calcário e xisto expandido), métodos de teste (corpos de prova pré-carregados e aquecidos, corpos de prova sem tensão e aquecidos e corpos de prova sem tensão e resfriados após o aquecimento), resistências de concreto (variando de 22,8 a 44,8 MPa) e temperaturas (de $93^{\circ} \mathrm{C}$ a $871^{\circ} \mathrm{C}$ ). Os corpos de prova foram cilindros de $75 \times 150 \mathrm{~mm}$.

Os dados foram importantes, pois foram usados como referência principal nas normas atuais da $\mathrm{ACl}$ para o projeto de concreto submetido a elevadas temperaturas (WILLAM et al., 2009). Desde que Abrams demonstrou a sensibilidade à diferentes estados de tensão do concreto aquecido, muitos pesquisadores estudaram o comportamento do concreto a diferentes estados de tensão, em sua maioria resfriados à temperatura ambiente (XIAO et al., 2016). A figura 1 apresenta os dados obtidos por Abrams para concretos com agregados calcários e silicosos.

Castillo et al. (1990) investigaram o efeito da temperatura elevada na resistência do concreto convencional e no concreto de alta resistência (31,1 a $89 \mathrm{MPa}$ ). Foram utilizados corpos de prova cilíndricos de concreto de $51 \mathrm{~mm} \times 102 \mathrm{~mm}$ de dimensões. No caso dos corpos de prova sob tensão, foi aplicada uma força de compressão equivalente a $40 \%$ da resistência de compressão do concreto sob temperatura ambiente, enquanto os mesmos foram aquecidos. Segundo os autores, a perda na resistência de ambos os concretos (convencional e alta resistência) aparentou seguir uma tendência parecida para temperaturas acima de $300^{\circ} \mathrm{C}$, conforme pode-se ver na Figura 2. 

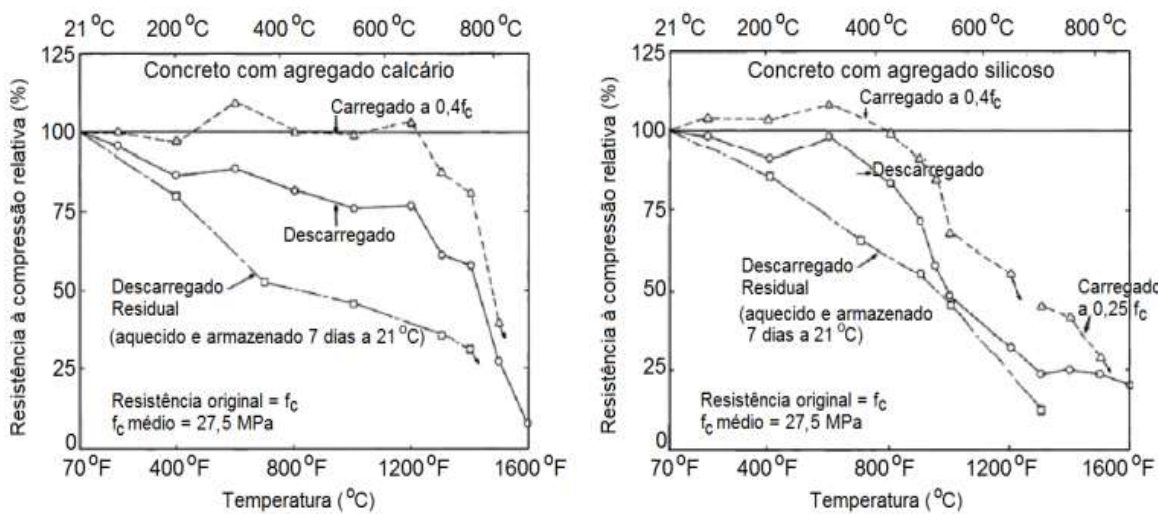

Figura 1: Efeito da temperatura na resistência do concreto com agregados calcários e silicosos. Fonte: Abrams (1971).

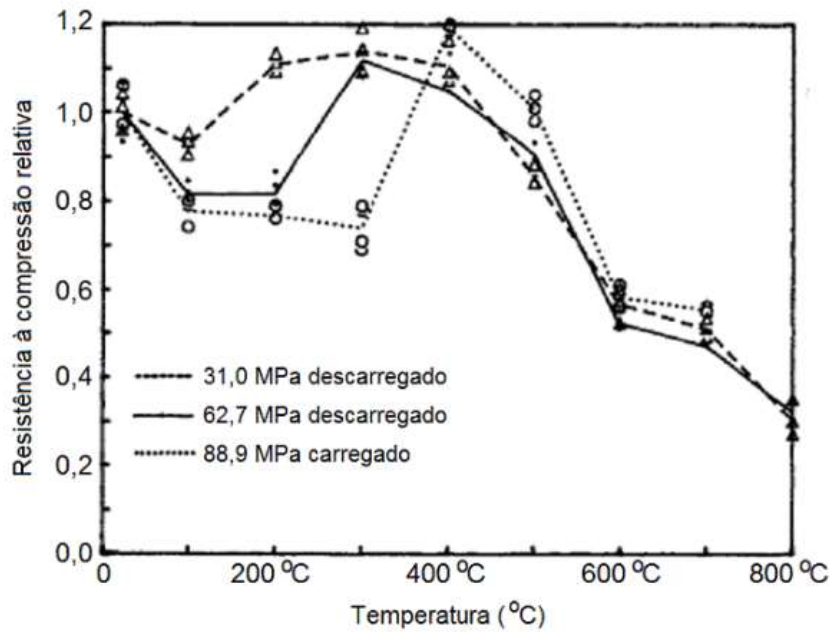

Figura 2: Efeito da temperatura na resistência do concreto. Fonte: Castillo et al. (1990).

Verifica-se nas Figura 1 e Figura 2 que em alguns casos até $400{ }^{\circ} \mathrm{C}$ observou-se um aumento na resistência à compressão do concreto, com relação ao concreto à temperatura ambiente. Além de Abrams (1971) e Castillo et al. (1990), este comportamento foi observado por diversos outros pesquisadores, como Lankard et al. (1971), Xu et al. (2001), Hachemi et al. (2014) e Guo et al. (2011). A explicação para tal fato é que a água adsorvida na pasta de cimento atenua as forças entre as partículas (forças de Van der Waals). Com a perda de água, as partículas tendem a se aproximar, aumentando a sua coesão.

Este comportamento não é, contudo, observado sempre. Como a água evapora podendo causar microfissuras no concreto, tais microfissuras tendem a reduzir a resistência à compressão do mesmo. Assim, o ganho ou perda de resistência deve-se ao equilíbrio entre o aumento da coesão das partículas e a redução da resistência devido a formação de microfissuras. A quantidade de umidade presente no concreto após a cura depende do tamanho do corpo de prova de concreto e das condições de temperatura e humidade relativa. A taxa de aquecimento e o tempo de exposição a elevadas temperaturas também afetam a umidade quando da realização dos ensaios (CASTILLO et al., 1990).

Assim, o incremento real na resistência à compressão reportada da literatura até temperaturas em torno de $400^{\circ} \mathrm{C}$ (algumas vezes após uma perda de resistência inicial a temperaturas mais baixas) pode ser parcialmente explicado com base na umidade livre presente nos corpos de prova de concreto durante a realização do ensaio. Até $121^{\circ} \mathrm{C}$ a remoção de água pode não ser completa e um efeito enfraquecedor pode 
ser observado. A temperaturas mais elevadas, os corpos de prova de concreto encontram-se mais desidratados e, portanto, mais resistentes (LANKARD et al., 1971).

\section{Uso de fibras para minimizar o impacto das elevadas temperaturas}

Para minimizar os efeitos deletérios da elevação da temperatura no concreto, o uso de fibras tem sido estudado por diversos pesquisadores. As fibras podem possuir diversos tamanhos e podem ser constituídas de diversos materiais, como polipropileno, aço e vidro. De fato, o Eurocode 2 indica a inclusão de $2 \mathrm{~kg} / \mathrm{m}^{3}$ de fibras de polipropileno para a redução do efeito spalling. As fibras de polipropileno são combustíveis, mas tal característica não é um problema quando as fibras são submetidas a elevadas temperaturas e fazem parte da matriz cimentícia. Elas fundem-se e volatilizam-se durante o fogo, criando canais e aumentando a porosidade. Esta propriedade das fibras tem sido utilizada para promover uma proteção adicional ao fogo, tendo em vista que os canais criam uma 'rota de escape' para o vapor que é formado durante um incêndio, minimizando o spalling do concreto devido às elevadas pressões formadas pelo vapor (BENTUR et al., 2007). Devido ao ponto de fusão ser similar ao das fibras de polipropileno, esperase um efeito similar com o uso das fibras de poliolefina.

\section{MATERIAIS E MÉTODOS}

A realização da presente pesquisa seguiu os seguintes passos: 10 Foram confeccionados corpos de prova de concreto cilíndricos de $100 \mathrm{~mm}$ x $200 \mathrm{~mm}$ de dimensões, onde o parâmetro variado foi o teor volumétrico das fibras de poliolefina $(\mathrm{Vf}=0,0 \%, \mathrm{Vf}=0,25 \%, \mathrm{Vf}=0,50 \%$ e $\mathrm{Vf}=0,75 \%)$. O teor volumétrico das fibras foi adotado conforme as especificações do fabricante, que indica Vf entre 0,25\% e 0,75\%; 2 으 Foram ensaiados seis corpos de prova a cada temperatura (ambiente, $300{ }^{\circ} \mathrm{C}, 600{ }^{\circ} \mathrm{C}$ e $900{ }^{\circ} \mathrm{C}$ ) e cada teor volumétrico de fibras; 3 ㅇ Foram utilizados dois fornos mufla, que aqueceram os corpos de prova a uma taxa de até $20^{\circ} \mathrm{C}$ por minuto. Após a temperatura alvo ser atingida, os corpos de prova continuaram a exposição por mais seis horas, para garantir a uniformidade da temperatura em seu interior. A taxa utilizada foi bastante rigorosa, sendo superior à maioria dos estudos semelhantes; 4ํ Após o aquecimento, os fornos eram desligados e os corpos de prova deixados em seu interior para o resfriamento até a temperatura ambiente, sendo retirados dos fornos no dia seguinte. Esta medida foi feita para evitar a formação de um gradiente térmico que pudesse causar fissurações nos corpos de prova devido à mudança brusca de temperatura; 5으 Dos seis corpos de prova, três foram submetidos aos ensaios de Ultrassom (V), Variação Volumétrica (?V), Perda de Massa (]m), Resistência à Compressão $\left(f_{c}\right)$ e Módulo de Elasticidade Tangente Inicial ( $\left.E_{c i}\right)$; 6o Os outros três corpos de prova foram submetidos aos ensaios de Porosidade (n) e Resistência à Tração Indireta por Compressão Diametral ( $f_{c t, s p}$ ); 70 Desta forma, foram confeccionados e ensaiados 96 corpos de prova no total.

Para a realização dos ensaios, foram utilizadas as prescrições das normas ABNT NBR 5739 (2007), ABNT NBR 8522 (2008), ABNT NBR 8802 (2013), ABNT NBR 7222 (2011) e ABNT NBR 9778 (2005). Com relação ao ensaio de perda de massa, o mesmo foi executado pesando-se os corpos de prova de concreto antes e 
depois do aquecimento, quando o corpo de prova resfriado à temperatura ambiente, sendo calculada a diferença entre as duas pesagens.

Para o ensaio de variação volumétrica, os corpos de prova foram medidos em três pontos distintos em seu comprimento (L) e diâmetro (D), sendo calculados os valores médios de L e D. Este procedimento foi executado antes de depois do aquecimento, com o corpo de prova resfriado à temperatura ambiente. Com os valores obtidos, era então calculado o volume dos corpos de prova antes e após o aquecimento.

\section{Materiais utilizados}

O cimento usado para a produção do concreto foi o cimento portland CPII F 32, facilmente encontrado no mercado local onde foram realizados os ensaios. Os agregados utilizados foram a brita 0, brita 1 e areia cuja granulometria é apresentada na Tabela 1 . Foi utilizado o superplastificante Tec-Flow 7000, fabricado pela empresa Grace Construction Products. O superplastificante foi utilizado para garantir a trabalhabilidade das composições com maior teor de fibra. A fibra utilizada foi fornecida pela empresa Geobrugg, possuindo as seguintes características dispostos no Quadro 1. A Figura 3 ilustra as fibras de poliolefina utilizadas envoltas em capa plástica, conforme fornecidas pelo fabricante.

Tabela 1: Granulometria da areia.

\begin{tabular}{|l|l|l|l|l|l|l|}
\hline Abertura da peneira $(\mathrm{mm})$ & 2,4 & 1,2 & 0,6 & 0,3 & 0,15 & Fundo \\
\hline \% retida individual & $0,00 \%$ & $7,48 \%$ & $45,85 \%$ & $30,97 \%$ & $14,39 \%$ & $1,31 \%$ \\
\hline \% retida acumulada & $0,00 \%$ & $7,48 \%$ & $53,33 \%$ & $84,30 \%$ & $98,69 \%$ & $100,00 \%$ \\
\hline Dimensão máxima característica & 2,4 & & & & & \\
\hline
\end{tabular}

Quadro 1: Tipo de fibra usada.

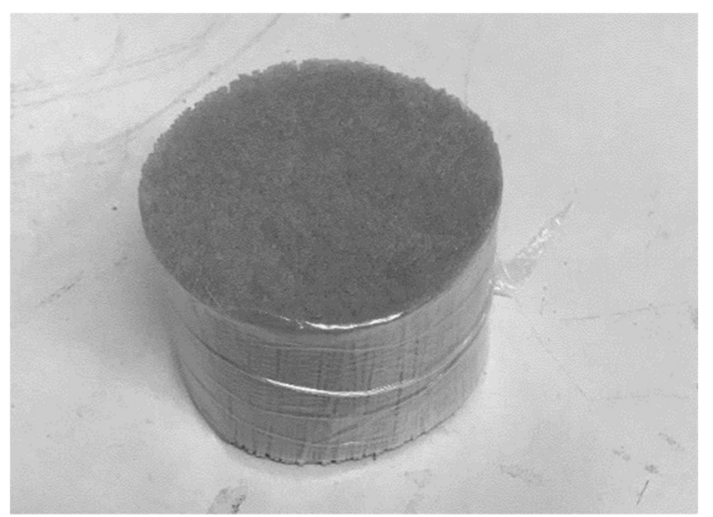

Figura 3: Fibras de poliolefina.

\section{Composição do concreto}

A composição do concreto foi calculada conforme THOMAZ e CARNEIRO (2008), tomando como base a resistência de $35 \mathrm{MPa}$, e é apresentado na Tabela 2. 
Tabela 2: Consumo de materiais em $\mathrm{kg} / \mathrm{m}^{3}$.

\begin{tabular}{|l|l|l|l|l|l|l|l|}
\hline Concreto & Cimento $(\mathrm{kg})$ & Superplastificante (I) & Água (I) & Areia (kg) & Brita 0 (kg) & Brita 1 (kg) & Fibras (\% vol) \\
\hline C35-F0,0 & 373 & 1,3 & 182 & 798 & 488 & 488 & 0 \\
\hline C35-F0,25 & 373 & 1,3 & 182 & 798 & 488 & 488 & 0,25 \\
\hline C35-F0,50 & 373 & 1,3 & 182 & 798 & 488 & 488 & 0,50 \\
\hline C35-F0,75 & 373 & 1,3 & 182 & 798 & 488 & 488 & 0,75 \\
\hline
\end{tabular}

\section{RESULTADOS E DISCUSSÃO}

\section{Spalling dos corpos de prova}

Durante o aquecimento dos corpos de prova de concreto, foi verificada a ocorrência de spalling nos corpos de prova de concreto sem fibras submetidos a temperaturas de $600{ }^{\circ} \mathrm{C}$ e $900{ }^{\circ} \mathrm{C}$. Todos os corpos de prova de concreto sem fibras apresentaram spalling. De fato, a explosão era de magnitude tal que chegou a danificar o revestimento interno do forno utilizado para aquecer o referido concreto. A Figura 4 mostra um corpo de prova de concreto após o spalling, ainda dentro do forno.

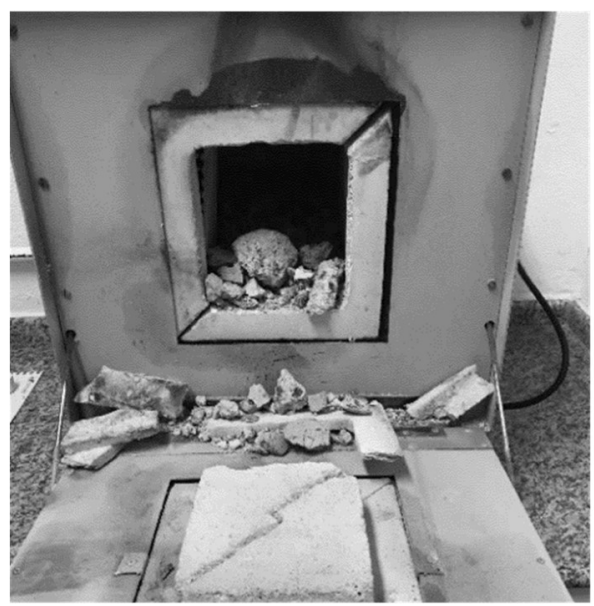

Figura 4: Spalling em corpo de prova de concreto.

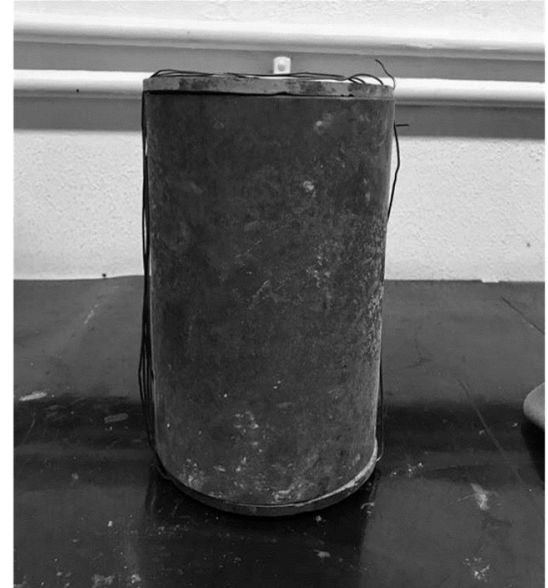

Figura 5: Corpo de prova de concreto encamisado para o aquecimento.

Para manter a integridade dos fornos, os corpos de prova de concreto sem fibras passaram a ser encamisados, conforme ilustra a Figura 5. A Figura 6 mostra um corpo de prova de concreto após spalling dentro do encamisamento. De 12 corpos de prova de concreto sem fibras que deveriam ser aquecidos, todos apresentaram spalling. 


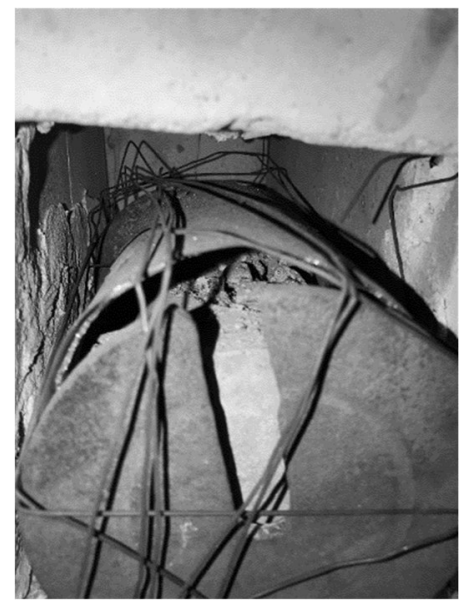

Figura 6: Corpo de prova de concreto após spalling dentro do encamisamento.

O spalling foi decorrente, provavelmente, da taxa de aquecimento dos fornos utilizados. Embora a taxa média ficou em $13{ }^{\circ} \mathrm{C} / \mathrm{min}$, a mesma atingia picos de $20{ }^{\circ} \mathrm{C} / \mathrm{min}$. Para o aquecimento a $300{ }^{\circ} \mathrm{C}$, esta situação não foi tão problemática, pois a aproximadamente $200^{\circ} \mathrm{C}$ a taxa de aquecimento era reduzida para menos de $10{ }^{\circ} \mathrm{C} / \mathrm{min}$. Para as temperaturas de $600^{\circ} \mathrm{C}$ e $900^{\circ} \mathrm{C}$, contudo, a redução para menos de $10^{\circ} \mathrm{C} / \mathrm{min}$ somente ocorreu após $450^{\circ} \mathrm{C}$. Essa taxa de aquecimento é superior à taxa de aquecimento utilizada por diversos outros pesquisadores, os quais não verificaram a ocorrência do fenômeno na totalidade dos corpos de prova de concreto com ou sem fibras (CHEN et al., 2004; POON et al., 2004; NOUMOWE, 2005; LAU et al., 2006; PENG et al., 2006). Portanto, para o concreto sem fibras, os resultados dos ensaios limitam-se à temperatura ambiente e de $300{ }^{\circ} \mathrm{C}$. Verificou-se ainda que nenhum dos corpos de prova de concreto com fibras sofreu spalling.

\section{Resistência à Compressão $\left(f_{c}\right)$}

Na Figura 7 verifica-se que o melhor resultado obtido foi com relação ao concreto com $0,50 \%$ de fibras, seguido pelo concreto com $0,25 \%$ de fibras. De fato, estes dois concretos tiveram um aumento na sua resistência a compressão quando submetidos a temperatura de $300{ }^{\circ} \mathrm{C}$, consonante com o discutido no item 2.2. Para uma melhor visualização dos resultados, foi comparada a resistência de cada composição de concreto com fibras com relação ao concreto sem fibras (Figura 8), até a temperatura de $300{ }^{\circ} \mathrm{C}$, a partir do qual houve spalling, o que impediu o comparativo.

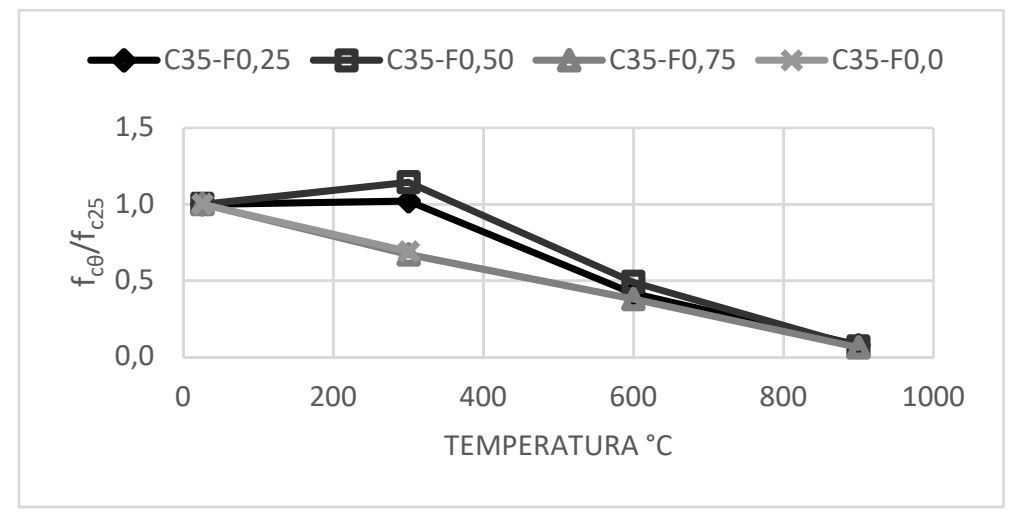

Figura 7: Resistência compressão. 


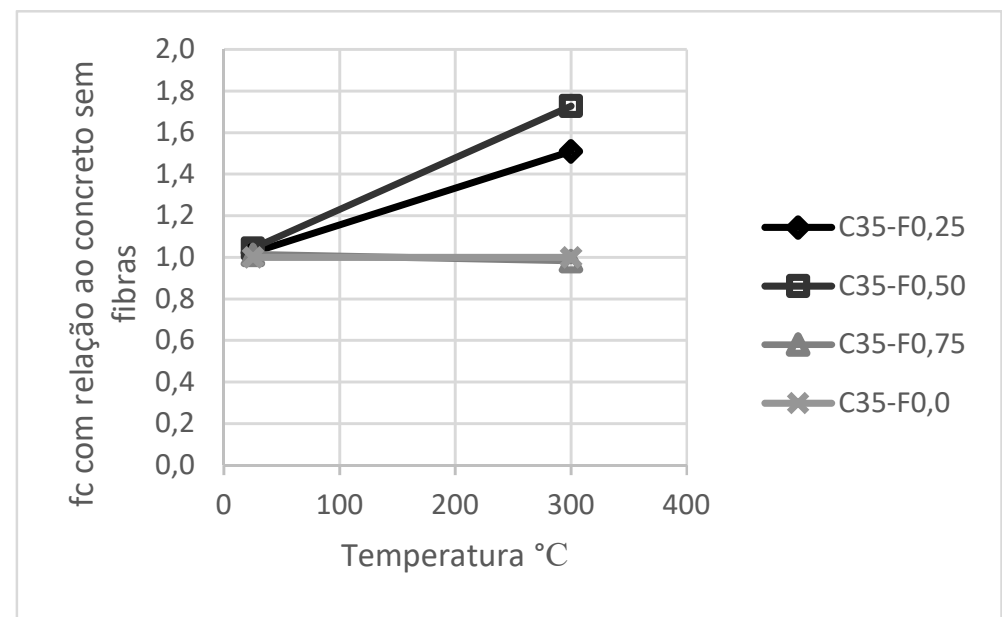

Figura 8: Resistência com relação ao concreto sem fibras.

Neste caso, pôde ser observado que a adição de fibras praticamente não alterou a resistência a temperatura ambiente. Porém, aos $300{ }^{\circ} \mathrm{C}$, os concretos $\mathrm{C} 35-\mathrm{F} 0,25$ e C35-F0,50 tiveram uma diferença de até $70 \%$ com relação ao concreto sem fibras. O concreto C35-F0,75 mostrou comportamento semelhante ao concreto sem fibras, provavelmente devido ao fato de que as fibras tornaram-no muito poroso, o que contribuiu para não haver melhoras com relação ao concreto sem fibras.

\section{Módulo de Elasticidade Tangente Inicial $\left(\mathrm{E}_{\mathrm{c} i}\right)$}

Neste caso, os concretos C35-F0,25 e C35-F0,50 também mostraram a melhor resposta à elevação de temperatura (Figura 9). O concreto C35-F0,75 mostrou uma perda maior de E do que o concreto sem fibras a $300^{\circ} \mathrm{C}$. A partir de $600{ }^{\circ} \mathrm{C}$, porém, todos os concretos mostraram uma resposta semelhante.

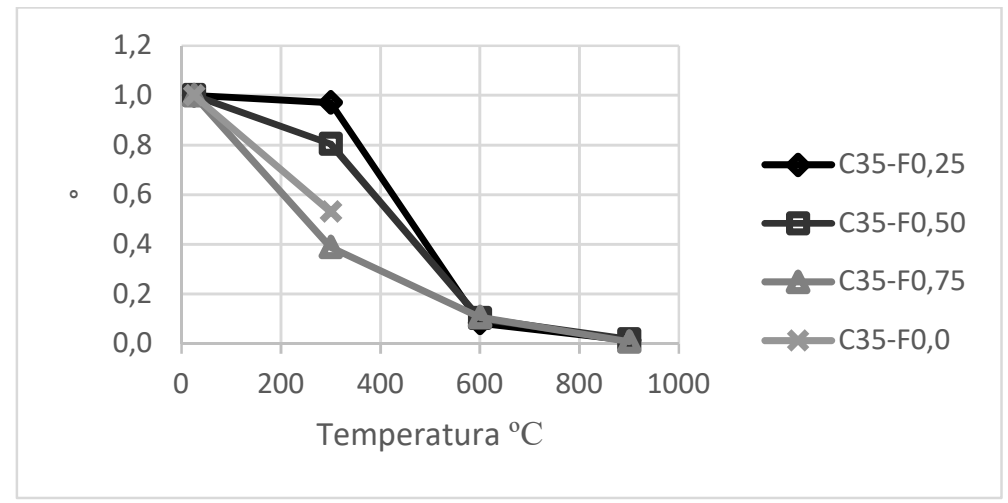

Figura 9: Módulo de Elasticidade.

\section{Perda de Massa ([m)}

Todas as composições aproximaram-se quanto a perda de massa até a temperatura de $300^{\circ} \mathrm{C}$ (Figura 10). À temperatura de $611^{\circ}$, porém, a composição C35-F0,25 mostrou a menor perda de massa, e a composição $\mathrm{C} 35-\mathrm{F0}, 50$ teve a maior perda de massa. A $900{ }^{\circ} \mathrm{C}$, porém, a perda de massa foi similar para todas as composições. 


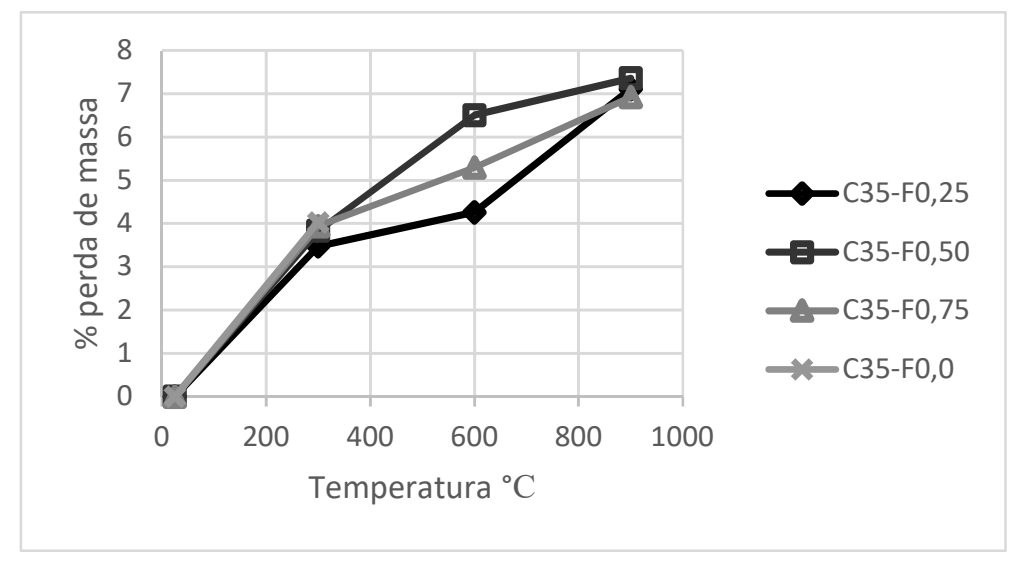

Figura 10: Perda de massa.

\section{Variação Volumétrica (回)}

A variação volumétrica foi calculada com a média da altura e diâmetro dos corpos de prova de concreto em três pontos diferentes e, após o aquecimento, os mesmos pontos foram medidos e calculada a nova média. Com os dados obtidos, foi calculado o volume do corpo de prova de concreto antes e depois do aquecimento, obtendo-se o valor da deformação. Os resultados encontrados mostraram que até $300{ }^{\circ} \mathrm{C} o$ concreto C35-F0,0 teve a menor variação. A maior variação foi encontrada no concreto C35-F0,50, conforme ilustra a Figura 11.

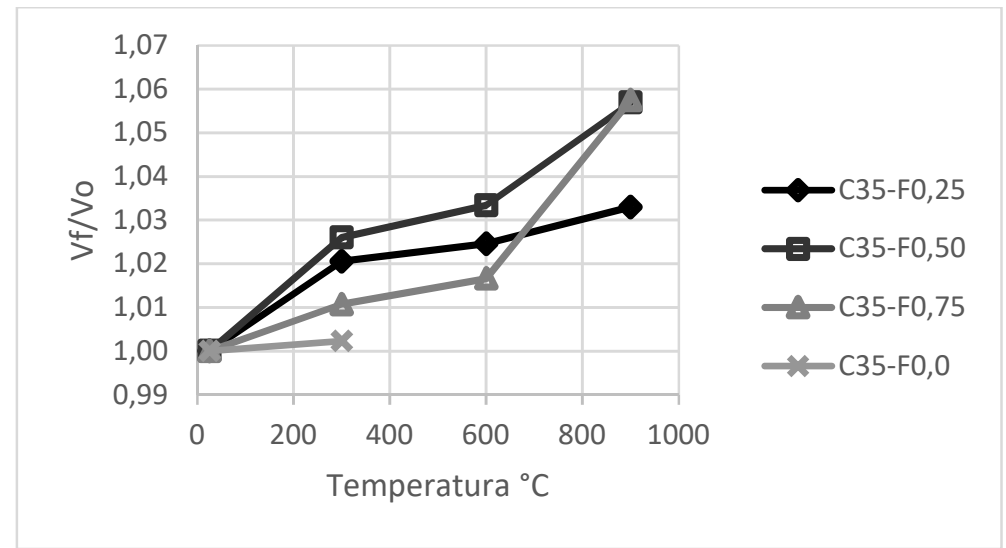

Figura 11: Variação Volumétrica.

\section{Ultrassom (V)}

Do gráfico encontrado (Figura 12), verificou-se que a variação de $V$ foi semelhante para todas as composições, havendo uma maior diferença a $300{ }^{\circ} \mathrm{C}$, onde o concreto $\mathrm{C} 35-\mathrm{F} 0,75$ mostrou uma perda mais significativa. Porém, a temperaturas maiores, os valores voltaram a se aproximar.

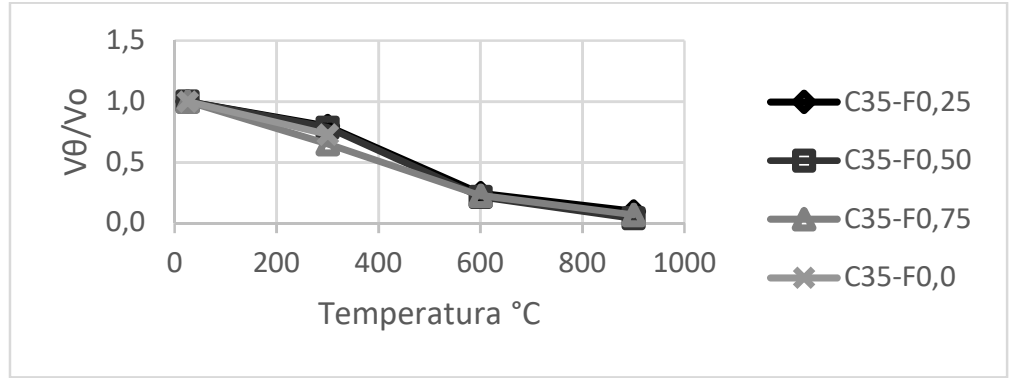

Figura 12: Ultrassom. 


\section{Resistência à Tração Indireta por Compressão Diametral (f $\left.f_{c t, s p}\right)$}

Nota-se pela Figura 13 que a $300^{\circ} \mathrm{C}$ o concreto sem fibras apresentou a menor perda relativa neste caso, sendo porém muito próximo dos outros concretos. A $600{ }^{\circ} \mathrm{C}$ pôde ser verificado que a perda da resistência esteve diretamente relacionada à quantidade de fibras, enquanto a $900{ }^{\circ} \mathrm{C}$, os valores voltaram a se aproximar. Para melhor analisar o presente ensaio, foi feito um gráfico que relaciona a resistência à tração de todos os concretos com fibras ao concreto sem fibras, da mesma maneira como realizado no item 3.1 (Figura 14).

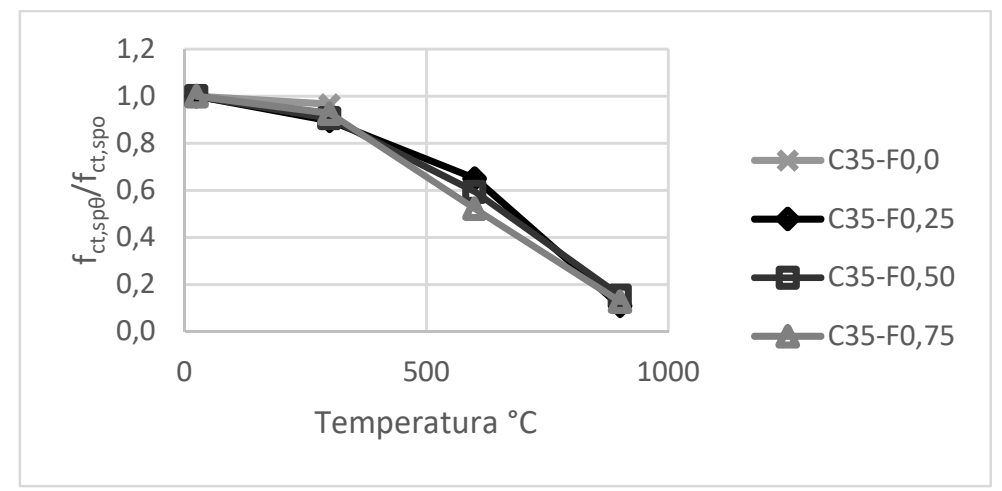

Figura 13: Resistência à Tração.

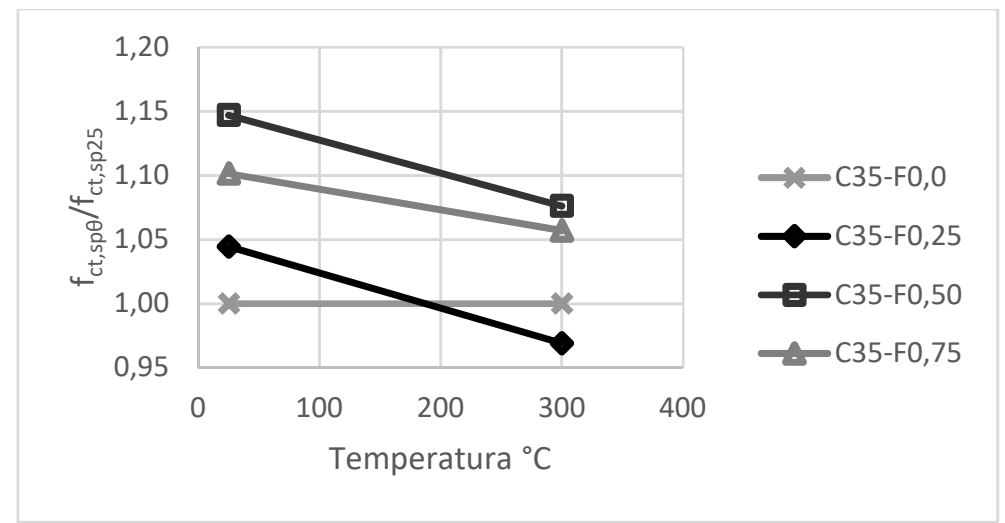

Figura 14: Resistência à tração com relação ao concreto sem fibras.

A adição de fibras de fato melhorou a resistência à tração à temperatura ambiente. A $300^{\circ} \mathrm{C}$, porém, a resistência apresentada por C35-F0,25 foi menor do que a apresentada por C35-F0,0, enquanto para teores de fibra maiores os valores ainda encontraram-se acima do concreto sem fibras. Desta forma, pôde-se concluir que, apesar de a adição de fibras ter piorado de maneira relativa esta propriedade mecânica do concreto, em termos absolutos houve ganho à temperatura ambiente e a $300^{\circ} \mathrm{C}$ para os concretos com maior teor de fibras.

\section{Porosidade (n)}

A porosidade foi determinada conforme precreve a norma ABNT NBR 9778 (2005). A partir dos resultados da norma, foi calculado o índice de vazios (e), sendo a porosidade (n) obtida através da Equação 1: 


$$
\mathrm{n}=\frac{\mathrm{e}}{1+\mathrm{e}}
$$

Nota-se pela Figura 15 que a composição C35-F0,50 apresentou a menor porosidade inicial. Porém, com o aumento da temperatura, começou a aproximar-se dos valores dos outros concretos com fibras.

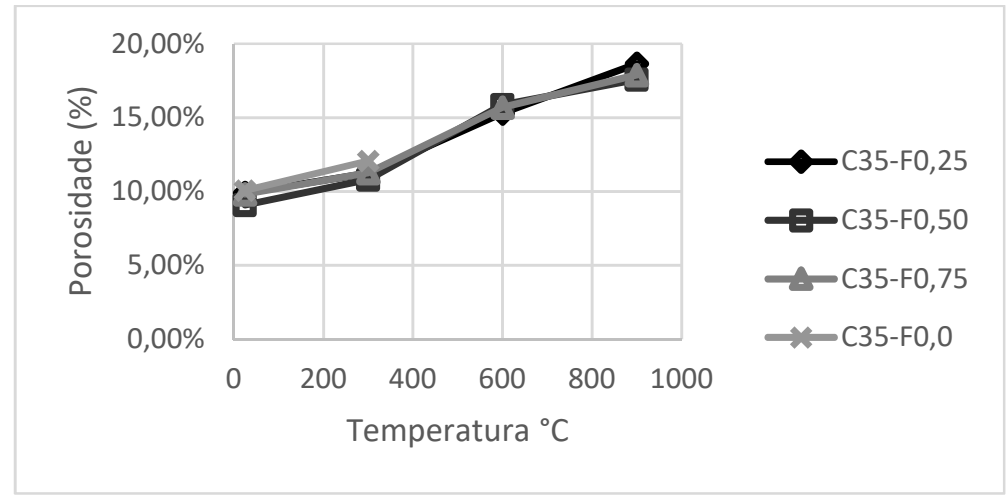

Figura 15: Porosidade.

O concreto sem fibras apresentou porosidade inicial próxima à apresentada pelos concretos com fibras. Contudo, com o aquecimento, a sua porosidade aumentou de maneira mais pronunciada, evidenciando um aumento na fissuração dos corpos de prova de concreto sem fibras maior do que o verificado nos corpos de prova de concreto com fibras. A composição C35-F0,75 apresentou a segunda maior porosidade a $300{ }^{\circ} \mathrm{C}$. Este resultado corroborou o encontrado no item 3.1, levando-se em conta a relação entre a porosidade e a resistência à compressão.

\section{CONCLUSÕES}

Neste estudo, foram executadas quatro composições de concreto com diferentes teores de fibras de poliolefina, a fim de que se pudesse investigar a resposta das amostras à exposição a elevadas temperaturas. os resultados obtidos, pode-se chegar às seguintes conclusões: - a adição de fibras melhorou as características mecânicas do concreto com relação ao concreto sem fibras, quando submetido a elevadas temperaturas; - a adição de fibras de poliolefina evitou o spalling em todos os corpos de prova de concreto; - o spalling verificado nos corpos de prova de concreto deu-se devido à taxa de aquecimento dos fornos relativametne elevada, chegando a $20^{\circ} \mathrm{C} / \mathrm{min}$; - a adição de fibras pouco interferiu na resistência à compressão do concreto sob temperatura ambiente; no concreto convencional, foi observado um aumento máximo de 5\% para o concreto C35-F0,50; no concreto de alta resistência C80-F0,25 ocorreu uma redução de $7 \%$; - sob $300{ }^{\circ} \mathrm{C}$, houve aumentos na resistência à compressão dos concretos com 0,25\% (média de aumento de $2 \%$ ) e $0,50 \%$ (média de aumento de $14 \%$ ) de teor volumétrico de fibra de poliolefina, em relação à resistência dos respectivos concretos sob temperatura ambiente, sendo que para $\mathrm{Vf}=0,75 \%$, não houve ganho de resistência, com fc ficando próximo ao concreto sem fibras; - sob temperatura ambiente, a adição de fibra de poliolefina pouco influenciou o valor do módulo de elasticidade do concreto; - a velocidade de propagação de onda ultrassônica decresceu com o aumento da temperatura e, em geral, com a adição de fibra de poliolefina; até a temperatura de $900^{\circ} \mathrm{C}$ e teor volumétrico de $0,75 \%$, as quedas no valor de $V$ foram, 
em média, 93\%; - a adição de fibras aumentou o valor de fct,sp no concreto sob temperatura ambiente até $15 \%$, para $\mathrm{Vf}=0,50 \%$; - com o aumento da temperatura, o valor de fct,sp diminuiu em até $89 \%$; - a elevação da temperatura aumentou a porosidade a até $18,66 \%$ e $16,97 \%$ sob $900{ }^{\circ} \mathrm{C}$; - a adição de $0,50 \%$ em volume de fibras mostrou no geral o valor com as maiores resistências mecânicas residuais; porém, para prevenção do spalling, todos os teores volumétricos de fibras foram adequados. Desta forma, a adição das fibras de poliolefina pode tornar-se uma alternativa viável para o uso em concretos cuja exposição a elevadas temperaturas deve ser levada em consideração.

\section{REFERÊNCIAS}

\section{ABRAMS, M. S.. Compressive strength of concrete at temperatures to 1600F. Detroit, 1971.}

AKCA, A. H.; ZIHNIOGLU, N. Ö.. High performance concrete under elevated temperatures. Construction and Building Materials, v.44, p.317-328, 2013.

ALBERTI, M. G.; ENFEDAQUE, A.; GÁLVEZ, J. C.. Comparison between oplyolefin fibre reinforced vibrated conventional concrete and self-compacting concrete. Construction and Building Materials, v.85, p.182-194, 2015.

ABNT. Associação Brasileira de Normas Técnicas. NBR 8802: Concreto endurecido: Determinação da velocidade de propagação de onda ultrassônica. Rio de Janeiro, 1994.

ABNT. Associação Brasileira de Normas Técnicas. NBR 9778: Argamassa e concreto endurecidos - Determinação da absorção de água por imersão - Índice de vazios e massa específica. Rio de Janeiro, 2005.

ABNT. Associação Brasileira de Normas Técnicas. NBR 5739: Concreto - Ensaio de compressão de corpos-de-prova cilíndricos. Rio de Janeiro. 2007.

ABNT. Associação Brasileira de Normas Técnicas. NBR 8522: Concreto - Determinação do módulo estático de elasticidade à compressão. Rio de Janeiro. 2008.

ABNT. Associação Brasileira de Normas Técnicas. ABNT NBR 7222: Argamassa e concreto - Determinação da resistência à tração por compressão diametral de corpos-de-prova cilíndricos. Rio de Janeiro, 2011.

BEHNOOD, A.; GHANDEHARI, M.. Comparison of compressive and splitting tensile strength of high-strength concrete with and without polypropylene fibers heated to high temperatures. Fire Safety Journal, v.44, p.1015-1022, 2009.

BENTUR, A.; MINDESS, S.. Fibre reinforced cementitious composites. 2 ed. United Kingdom, 2007.

CASTILLO, C.; DURRANI, A. J.. Effect of Transient High Temperature on High-Strength Concrete. ACI Materials Journal, v.87, n.1, p.47-53, 1990.

CHEN, B.; LIU, J.. Residual strength of hybrid-fiber-reinforced high-strength concrete after exposure to high temperatures. Cement and Concrete Research, v.34, p.1065-1069, 2004.
FIGUEIREDO, A. D.. Concreto com fibras: Ensino, Pesquisa e Realizações. IBRACON, v.02, p.1195-1225, 2005.

GUO, Z.; SHI, X.. Experiment and Calculation of Reinforced Concrete at Elevated Temperatures. 2011.

HACHEMI, S.; OUNIS, A.; CHABI, S.. Evaluating Residual Mechanical and Physical Properties of Concrete at Elevated Temperatures. International Journal of Civil, Environmental, Structural, Construction and Architectural Engeneering, v.8, n.2, p.176-181, 2014.

INSTITUTE, A. C.. ACl 216.1-97/TMS 0216.1-97: Standard Method for Determining Fire Resistance of Concrete and Masonry Construction Assemblies. 1997.

KALIFA, P.; CHÉNÉ, G.; GALLÉ, C.. High-temperature behaviour of HPC with polypropylene fibres: From spalling to microstructure. Cement and Concrete Research, v.31, p.1487-1499, 2001.

LANKARD, D. R.; BIRKIMER, D. L.; FONDRIEST, F. F.; SNYDER, M. J.. Effects of Moisture Content on the Structural Properties of Portland Cement Concrete Exposed to Temperatures up to 500F. Temperature and Concrete, Detroit, v.11, n.1, p.59-102, 1971.

LAU, A.; ANSON, M.. Effect of high temperatures on high performance steel fibre reinforced concrete. Cement and Concrete Research, v.36, p.1698-1707, 2006.

LIN, W. T.; CHENG, A.; HUANG, R.; CHEN, Y. C.; ZHOU, X. G.. Effect of polyolefin fiber on the engineered properties of cement-based composites containing silica fume. Seul: International Association for Automation and Robotics in Construction. 2011.

MEHTA, P. K.; MONTEIRO, P. J. M.. Concreto: Microestrutura, Propriedades e Materiais. 2 ed. São Paulo, 2014.

MILLER, K. P.. Estudo da fluência em vigas de concreto reforçado com fibras de aço, com aplicação de conceitos da mecânica da fratura. São Carlos, 2008.

NOUMOWE, A.. Mechanical properties and microstructure of high strength concrete containing polypropylene fibres exposed to temperatures up to $2000^{\circ}$. Cement and Concrete Research, v.35, p.2192-2198, 2005. 
PENG, G. F.; YANG, W. W.; ZHAO, J.; LIU, Y. F.; BIAN, S. H.; ZHAO, L.H.. Explosive spalling and residual mechanical properties of fiber-toughened high-performance concrete subjected to high temperatures. Cement and Concrete Research, v.36, p.723-727, 2006.

POON, C. S.; SHUI, Z. H.; LAM, L.. Compressive behavior of fiber reinforced high-performance concrete subjected to elevated temperatures. Cement and Concrete Research, v.34, p.2215-2222, 2004.

THOMAZ, E. C. S.; CARNEIRO, L. A. V.. Concretos de alta resistência: tendências das composições. Concreto \& Construções, p.59-63, 2008.
WILLAM, K.; XI, Y.; LEE, K.; KIM, B.. Thermal response of reinforced concrete structures in nuclear power plants. Boulder, 2009.

XIAO, J.; LI, Z.; XIE, Q.; SHEN, L.. Effect of strain rate on compressive behaviour of high-strength concrete after exposure to elevated temperatures. Fire Safety Journal, v.83, p.25-37, 2016.

XU, Y.; WONG, Y. L.; POON, C. S.; ANSON, M.. Impact of high temperature on PFA concrete. Cement and Concrete Research, v.31, p.1065-1073, 2001.

A CBPC - Companhia Brasileira de Produção Científica (CNPJ: 11.221.422/0001-03) detém os direitos materiais desta publicação. Os direitos referem-se à publicação do trabalho em qualquer parte do mundo, incluindo os direitos às renovações, expansões e disseminações da contribuição, bem como outros direitos subsidiários. Todos os trabalhos publicados eletronicamente poderão posteriormente ser publicados em coletâneas impressas sob coordenação da Sustenere Publishing, da Companhia Brasileira de Produção Científica e seus parceiros autorizados. Os (as) autores (as) preservam os direitos autorais, mas não têm permissão para a publicação da contribuição em outro meio, impresso ou digital, em português ou em tradução. 